\title{
A Cost-Effective Technique for Pure Laparoscopic Live Donor Nephrectomy
}

\author{
Tiberio M. Siqueira Jr, Anuar I. Mitre, Fabiano A. Simoes, Andre F. Maciel, Alvaro M. Ferraz, \\ Sami Arap
}

Kidney Transplantation Center (TMS, AFM, AMF) General Hospital, Federal University of

Pernambuco, Recife, Pernambuco, Brazil, and Kidney Transplantation Center (AIM, FAS, SA)

General Hospital, University of Sao Paulo, USP, Sao Paulo, Brazil

\begin{abstract}
Objective: Compare two different techniques for laparoscopic live donor nephrectomy (LDN), related to the operative costs and learning curve.

Materials and Methods: Between April/2000 and October/2003, 61 patients were submitted to LDN in 2 different reference centers in kidney transplantation. At center A (CA), 11 patients were operated by a pure transperitoneal approach, using Hem-O-Lok ${ }^{\circledR}$ clips for the renal pedicle control and the specimens were retrieved manually, without using endobags. At center B (CB), 50 patients were also operated by a pure transperitoneal approach, but the renal pedicles were controlled with endo-GIA appliers and the specimens were retrieved using endobags.

Results: Operative time $(231 \pm 39 \mathrm{~min}$ vs. $179 \pm 30 \mathrm{~min} ; \mathrm{p}<0.000)$, warm ischemia time $(5.85 \pm 2.85 \mathrm{~min}$ vs. $3.84 \pm 3.84$ $\min ; \mathrm{p}=0.002)$ and blood loss $(214 \pm 98 \mathrm{~mL}$ vs. $141 \pm 82 \mathrm{~mL} ; \mathrm{p}=0.02)$ were statistically better in $\mathrm{CB}$, when compared to CA. Discharge time was similar in both centers. One major complication was observed in both centers, leading to an open conversion in CA $(9.1 \%)$. One donor death occurred in CB (2\%). Regarding the recipients, no statistical difference was observed in all parameters analyzed. There was an economy of US $\$ 1.440$ in each procedure performed in CA, when compared to CB.

Conclusions: Despite the learning curve, the technique adopted by CA, showed no deleterious results to the donors and recipients when compared with the $\mathrm{CB}$. On the other hand, this technique was cheaper than the technique performed in the $\mathrm{CB}$, representing an attractive alternative for LDN, mainly in developing centers.
\end{abstract}

Key words: kidney transplantation; nephrectomy; laparoscopy; costs and cost analysis

Int Braz J Urol. 2006; 32: 23-30

\section{INTRODUCTION}

Since the first laparoscopic nephrectomy (LN) was performed by Clayman et al. (1), many urological procedures have been done using this approach $(2,3)$. In 1995, Ratner et al. (4) described the first pure LDN and later, Wolf et al. (5) described the first hand-assisted LDN. Many authors have compared the laparoscopic approach with the conventional open approach for live renal procurement, observing similar results (6-8).

In fact, both laparoscopic techniques (pure and hand-assisted) show advantages and disadvantages when compared to each other and both show two important disadvantages when compared to the open approach: the learning curve and the operative costs. 
Herein, the authors compare two different techniques adopted in two referral centers in renal transplantation, pointing out the operative costs and the learning curve.

\section{MATERIALS AND METHODS}

The first 11 left LDN performed between January and October 2003 in CA, were compared to the first 50 left LDN performed between April 2000 and August 2003 in CB.

In both centers, pure laparoscopic technique was adopted and harmonic scalpel (Ultracision ${ }^{\circledR}$, Ethicon Endosurgery, $\mathrm{OH}$ ) was used throughout the procedures, for renal pedicle dissection and vascular control of small vessels.

In the CA, the renal pedicle was controlled using Hem-O-Lok clips ${ }^{\circledR}$ (Weck Closure Systems, research triangle, CA). After release the whole kidney and ureter division, a modified Pfannenstiel incision was done (Figure-1) and the assistant's hand was inserted in the abdominal cavity without any hand-assist device (Figure-2), as described by Shalhav et al. (9). The kidney was lifted up by the assistant's fingers (Figure-3) and two large Hem-O-Lok ${ }^{\circledR}$ clips were applied to the renal artery and vein. Finally, the ves-

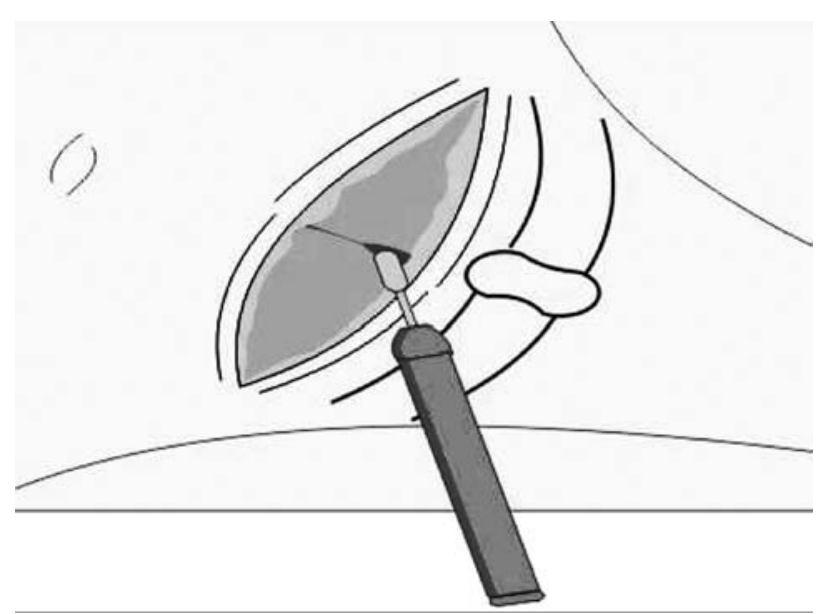

Figure 1 - Modified Pfannenstiel incision. The skin is opened horizontally and the aponeurosis is opened vertically (cruciform incision).
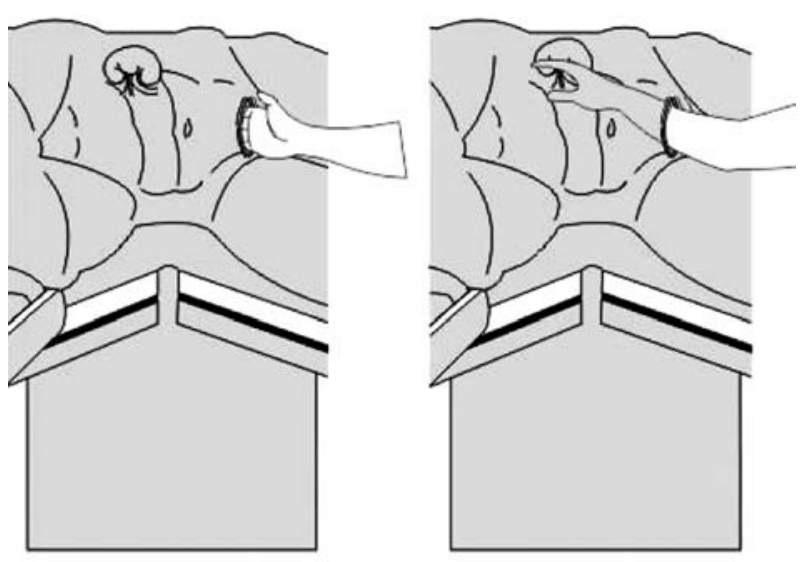

Figure 2 - Introduction of assistant's arm in the peritoneal cavity without using any hand-assist device.

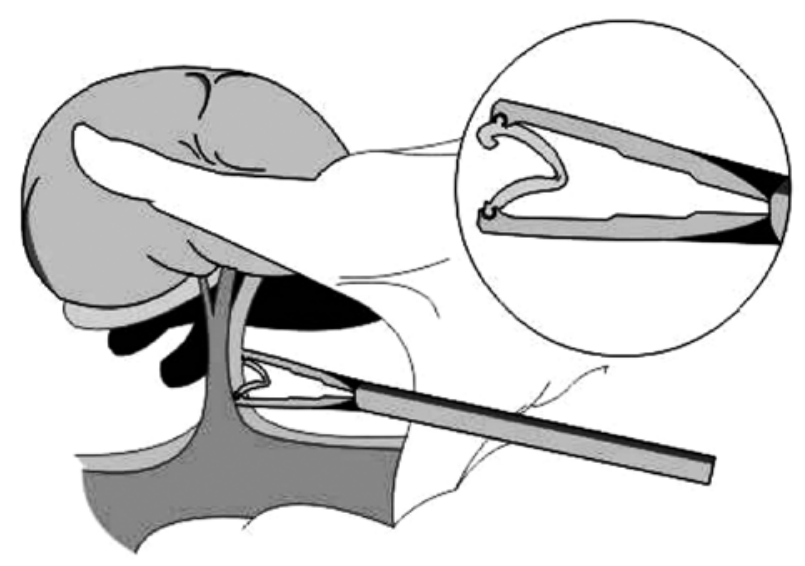

Figure 3 - Renal pedicle exposure between the assistant hand's fingers.

sels were divided and specimen was removed manually from the peritoneal cavity.

In the $\mathrm{CB}$, after release the whole kidney and ureter division, an endobag (EndoCatch bag $\mathrm{II}^{\circledR}$, Ethicon Endosurgery, $\mathrm{OH}$ ) was inserted in the peritoneal cavity through a Pfannenstiel incision and engulfed the kidney and ureter. Three metallic clips were applied to the renal artery and the renal vein was controlled and divided with an endo-GIA applier (ETSFlex ${ }^{\circledR} 35 \mathrm{~mm}$, Ethicon Endosurgery, Cincinnati, $\left.\mathrm{OH}\right)$. Finally, the renal artery was divided and the kidney was removed from the peritoneal cavity inside the endobag. 


\section{RESULTS}

A statistical difference was observed in all transoperative data when both groups are compared as seen in Table-1. In CA, one transoperative bleeding from the renal artery was observed, leading to urgent open conversion (9.1\%). Likewise, one transoperative complication was observed in the CB $(2 \%)$, represented by prolonged warm ischemia time due to inadvertent renal artery clipping (27 minutes). No open conversions were observed in the $\mathrm{CB}$.

On postoperative time, one major complication was observed in the $\mathrm{CA}(9.1 \%)$ and two in $\mathrm{CB}$ (4\%). One of these two complications in $\mathrm{CB}$, led the patient to death $(2 \%)$, caused by an unrecognized large bowel perforation and peritonitis (Table-2).

\section{Operative Costs}

In the first 40 of 50 procedures performed at $\mathrm{CB}$, the laparoscopic endo-GIA applier was used to control the renal vein. In the last ten cases, the HemO-Lok ${ }^{\circledR}$ clips were adopted to control this vessel. Moreover, in all procedures at this center, the endobag was used to remove the kidney from the peritoneal cavity. The asking price for both devices per procedure was US\$ 1480 (endo-GIA applier - US\$ 1000 and endobag - US\$ 480). On the other hand, only 4 Hem-O-Lok ${ }^{\circledR}$ clips were used per procedure in the CA, costing US\$ 40 (US\$ 10 each). Therefore, there was a savings of US\$ 1440 in each procedure performed in the CA, when compared with the CB.

Regarding the recipients, no statistical difference was observed in all parameters analyzed (Table-3, Figure-4).

\section{COMMENTS}

The $\mathrm{LN}$ is considered a complex procedure, requiring specific skills in laparoscopy. In average, 20-30 LN are required to overcome the learning curve

Table 1 - Transoperative data of donors.

\begin{tabular}{lccc}
\hline Transoperative Data & Center A & Results & Penter B \\
\hline Overall surgical time (min) & $231 \pm 39(160-305)$ & $179 \pm 30(120-270)$ & $<0.000$ \\
Warm ischemia time (min) & $5.85 \pm 2.85(3.5-11)$ & $3.84 \pm 3.84(1.2-27)$ & 0.002 \\
Blood loss (mL) & $214 \pm 98(80-440)$ & $141 \pm 82(30-350)$ & 0.02 \\
Major complications & $1(9.1 \%)$ & - & - \\
Bleeding from renal artery & - & $1(2 \%)$ & - \\
Inadvertent renal artery control & $1(9.1 \%)$ & & \\
Conversion to open procedure & & & \\
\hline
\end{tabular}

Table 2 - Postoperative data of donors.

\begin{tabular}{llll}
\hline Postoperative Data & Center A & Results & Penter B \\
\hline Major complications & $1(9.1 \%)$ & $2(4 \%)$ & - \\
Reoperations & $1(9.1 \%)$ & $2(4 \%)$ & - \\
Hospital stay (days) & $2.8(2-5)$ & $3.2(2-6)$ & - \\
Death & - & $1(2 \%)$ & - \\
\hline
\end{tabular}




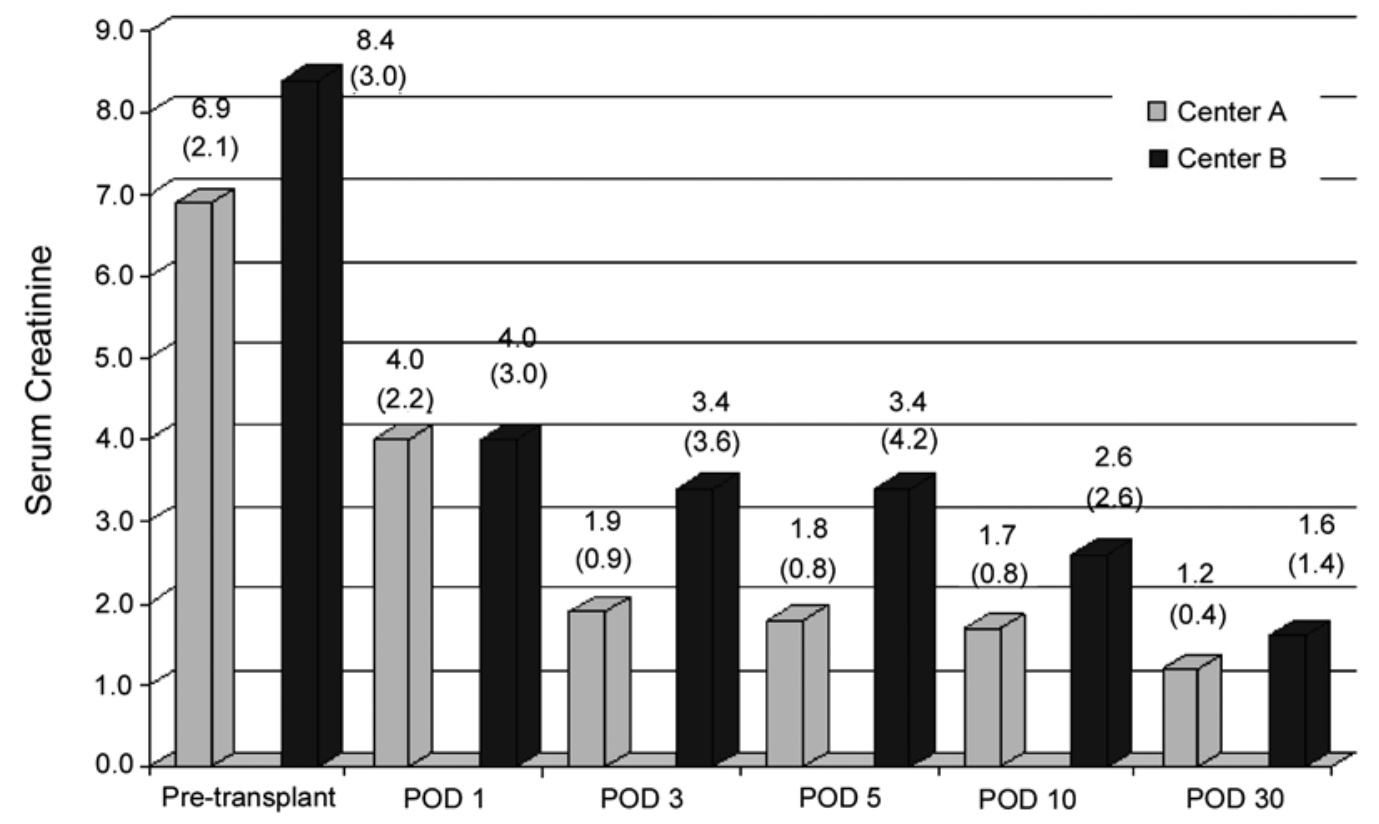

Figure 4 - Receptors data. Serum creatinine pre-and post-transplant.

(10). Beside this, it is advised to start a LDN program with two proficient surgeons in laparoscopy, in order to decrease the learning curve (11).

Comparing the transoperative data of both centers, one can note that $\mathrm{CB}$ already overcame the learning curve, but $\mathrm{CA}$ still is passing through this period (1,4,6-9). Nonetheless, no deleterious results were observed in CA donors, likewise, no difference was observed in the recipients when compared to $\mathrm{CB}$ recipients.
The second major impeachment that precludes the global dissemination of this technique is related with the operative costs. Some authors $(12,13)$ observed that the hospital costs for a $\mathrm{LN}$ were greater than for an open nephrectomy. Mullins et al. (12) evaluated the four available treatment options for renal chronic failure, based on Medicare data. After 2 years of follow-up, the highest costs were observed with the cadaveric donor procurement (US\$299,818), followed by laparoscopic live donor procurement

Table 3 - Overall data of recipients.

\section{Overall Data}

Delayed renal function

Transoperative complications

Postoperative complications

Acute/Chronic rejection

Graft lost

Death

\section{Results}

Center A

\section{Center B}

\begin{tabular}{ll}
$9.1 \%$ & $8 \%$ \\
1 & 1 \\
2 & 9 \\
$2 / 0(18.2 \%)$ & $4 / 2(12 \%)$ \\
$1(9.1 \%)$ & $2(4 \%)$ \\
$1(9.1 \%)$ & $2(4 \%)$ \\
\hline
\end{tabular}


(US\$296,636) and open live donor procurement (US\$ 257,271). Dialysis was the least expensive treatment (US\$ 147,460). Likewise, Pace et al. (13) showed that LDN is more expensive than the open donor nephrectomy (US\$10,317 vs. US\$9,853), but, on the other hand, the quality of life was considered better for the laparoscopic group (0.768 vs. 0.706). The authors concluded that the overall costs (hospital and social costs), allow the use of LDN for live kidney procurement.

Finally, Simforoosh et al. (14) recently published their experience with a new technique for LDN, in which the use of endo-GIA and endobags were changed by metallic clips and manual specimen retrieval. The authors observed an economy of U\$ 600 per procedure and concluded that this approach is safer and less costly when compared to the standard laparoscopic technique. Our experience is in congruence with the Iranian's data. The difference in the cost savings between both groups (US\$ 1440 vs. US\$ 600 ), probably is related with the exchange price charged in different countries.

The present study showed that the technique adopted by $\mathrm{CA}$ is cheaper than the technique employed in $\mathrm{CB}$, because the use of disposable devices as endo-GIA appliers or endobags was not used. Moreover, the manual specimen retrieval as proposed by Shalhav et al. (9), precluded the use of hand-assist devices, which costs range from US\$ 600 to US\$ 960. The additional costs related to the use of special disposable devices can rule out the employment of the laparoscopic live renal procurement in developing centers around the world.

\section{CONCLUSION}

Despite the learning curve, the technique adopted by the CA, showed no deleterious results to the donors and recipients when compared to CB. On the other hand, this technique was cheaper than the technique performed in $\mathrm{CB}$, representing an attractive alternative for LDN, mainly in developing centers.

\section{CONFLICT OF INTEREST}

None declared.

\section{REFERENCES}

1. Clayman RV, Kavoussi LR, Soper NJ, Dierks SM, Meretyk S, Darcy MD, et al.: Laparoscopic nephrectomy: initial case report. J Urol. 1991; 146: 278-82.

2. Denes FT, Mendonca BB, Arap S: Laparoscopic management of intersexual states. Urol Clin North Am. 2001; 28: 31-42.

3. Chan DY, Cadeddu JA, Jarrett TW, Marshall FF, Kavoussi LR: Laparoscopic radical nephrectomy: cancer control for renal cell carcinoma. J Urol. 2001; 166: 2095-9; discussion 2099-100.

4. Ratner LE, Ciseck LJ, Moore RG, Cigarroa G, Kaufman S, Kavoussi LR: Laparoscopic live donor nephrectomy. Transplantation. 1995; 15: 1047-9.

5. Wolf JS Jr, Tchetgen MB, Merion RM: Hand-assisted laparoscopic live donor nephrectomy. Urology. 1998; 52: 885-7.

6. Jacobs SC, Cho E, Dunkin BJ, Flowers JL, Schweitzer $\mathrm{E}$, Cangro C, et al.: Laparoscopic live donor nephrectomy: the University of Maryland 3-year experience. J Urol. 2000; 164: 1494-9.

7. Lee BR, Chow GK, Ratner LE, Kavoussi LR: Laparoscopic live donor nephrectomy: outcomes equivalent to open surgery. J Endourol. 2000; 14: 8119; discussion 819-20.

8. Siqueira TM Jr, Paterson RF, Kuo RL, Stevens LH, Lingeman JE, Shalhav AL: Comparison of laparoscopic live donor nephrectomy versus the traditional open technique. Int Braz J Urol. 2002; 28: 394401; discussion 401-2.

9. Shalhav AL, Siqueira TM Jr, Gardner TA, Paterson RF, Stevens LH: Manual specimen retrieval without a pneumoperitoneum preserving device for laparoscopic live donor nephrectomy. J Urol. 2002; 168: 941-4.

10. Higashihara E, Baba S, Nakagawa K, Murai M, Go H, Takeda M, et al.: Learning curve and conversion to open surgery in cases of laparoscopic adrenalectomy and nephrectomy. J Urol. 1998; 159: 650-3.

11. Siqueira TM Jr, Gardner TA, Kuo RL, Paterson RF, Stevens LH, Lingeman JE, et al.: One versus two proficient laparoscopic surgeons for laparoscopic live donor nephrectomy. Urology. 2002; 60: 406-9; discussion 409-10.

12. Mullins CD, Thomas SK, Pradel FG, Bartlett ST: The economic impact of laparoscopic living-donor nephrectomy on kidney transplantation. Transplantation. 2003; 75: 1505-12.

13. Pace KT, Dyer SJ, Phan V, Poulin EC, Schlachta CM, Mamazza J, et al.: Laparoscopic v open donor nephre- 
ctomy: a cost-utility analysis of the initial experience at a tertiary-care center. J Endourol. 2002; 16: 495508 .
14. Simforoosh N, Basiri A, Tabibi A, Shakhssalim N: Laparoscopic donor nephrectomy-an Iranian model for developing countries: a cost-effective no-rush approach. Exp Clin Transplant. 2004; 2: 249-53.

Accepted after revision: November 26, 2005
Correspondence address:

Dr. Tibério Moreno de Siqueira Jr.

Av. Agamenon Magalhães, 4775 / 201

Recife, PE, 50070-160, Brazil

Fax: + 5581 2125-7402

E-mail: tiberiojr@uol.com.br

\section{EDITORIAL COMMENT}

End-stage renal disease accounts for US\$ 17.9 billion annually in direct medical costs in the United States (1). Over the past years, LDN has been the standard approach for kidney retrieval in live donors in many centers. More than $60 \%$ of the centers in the USA currently perform LDN and numbers are rising in Europe as well (2).

The paper shows that the authors (both groups) have good experience with Laparoscopy. The operative time and warm ischemia time in Group CA is still high, but this is a complex laparoscopic procedure, and this learning curve will decrease with a larger number of cases (as shown by CB). An important fact is "no deleterious results were observed in CA donors and recipients". CA group shows a good alternative to a LDN, with a "better price" and the advantage that the kidney can be lift up by the assistant's hand at the time of hilum treatment and removed by the same person, not wasting time.

Early recovery of graft function, longer-term renal function, and patient and allograft survival are similar for live donor kidneys obtained by either a laparoscopic or an open surgical technique (3).

Advances in preoperative imaging and laparoscopic technique have enabled surgeons to extend the indications for live donor nephrectomy. The new generation of three-dimensional imaging facilitates operative planning and intraoperative dissection. Acquisition of laparoscopic skills has also enabled surgeons to perform donor nephrectomies on kidneys that would have been previously considered less suitable for donation (e.g. right-sided or with anomalous vasculature). As imaging and laparoscopic techniques continue to advance, it is expected that minimally invasive donor nephrectomy will continue to evolve (4).

\section{REFERENCES}

1. Mullins CD, Thomas SK, Pradel FG, Bartlett ST: The economic impact of laparoscopic living-donor nephrectomy on kidney transplantation. Transplantation. 2003; 75: 1505-12. 
2. Giessing M, Turk I, Roigas J, Schonberger B, Loening SA, Deger S: Laparoscopy for living donor nephrectomy-particularities of the currently applied techniques. Transpl Int. 2005; 18: 1019-27.

3. Derweesh IH, Goldfarb DA, Abreu SC, Goel M, Flechner SM, Modlin C, et al.: Laparoscopic live do- nor nephrectomy has equivalent early and late renal function outcomes compared with open donor nephrectomy. Urology. 2005; 65: 862-6.

4. Kieran K, Roberts WW: Laparoscopic donor nephrectomy: an update. Curr Opin Nephrol Hypertens. 2005; 14: 599-603.

Dr. Mauricio Rubinstein

Section of Endourology and Laparoscopy Federal Univ State Rio de Janeiro, UNIRIO

Rio de Janeiro, RJ, Brazil E-mail:mrubins@attglobal.net

\section{EDITORIAL COMMENT}

One of the major challenges related to minimally invasive surgery is the inherent cost of technology. In developing countries, the use of disposables such as trocars, vascular staplers, and endo-bags, raise intraoperative costs to such a level that makes the procedure prohibitive.

In this article, the authors present two modifications in the technique of live donor nephrectomy in order to minimize intraoperative costs. As such, they avoid the use of the Endo-GIA to control the renal vein and the use of Endo-bag to retrieve the graft. By doing so, they were able to reduce costs in up to US\$ 1400 for each procedure, without jeopardizing the safety of the donor and the quality of the graft. This is similar to what have already been assessed and reported by the Iranian group from the Beheshti University of Medical Science, which found a US\$ 600 decrease in operative costs in each nephrectomy (1).

In addition to reduce costs, the technique suggested by the authors have other advantages that are worth to be highlighted: 1) The Endo-GIA stapler, used to control the renal vein, has a potential malfunction rate of $1.7 \%$ that could lead to catastrophic donor bleeding and undesirable problems with the graft. In a review of 565 nephrectomies performed using the Endo-GIA stapler, the disposable device did not work properly in 10 cases. Nonetheless, the etiology of the failure included preventable causes in 7 cases and primary instrument failure in only 3 cases (2). 2) The Endo-GIA has a lower leak pressure when compared to the self-locking polymer clips (262 vs. $1220-1500 \mathrm{mmHg}$ ) and bleeding may occur in the donor through the staple line, between individual staples, under supra-physiologic arterial blood pressures (3). 3) The Endo-GIA applies 3 rows of staggered staples on either sides of the central cut, which result in a waste of $5-10 \mathrm{~mm}$ of vessel length after trimming the staples from the graft side. Moreover, one has to cut-off the staple line from the in order to vent the graft during perfusion (4). 4) Finally, the use of an Endo-bag to retrieve the graft, may prolong warm ischemia time since the graft has to be fitted within the bag prior to its extraction. In fact, using the hand actually helps to retract the graft laterally, allowing a better exposition of renal vessels, and quicker graft retrieval without the risk of graft slipping out of the bag. 
There is no doubt that lowering intra-operative costs is one goal to be achieved in developing countries. However, one should always bear in mind that the safety of the patient should never be compromised. Therefore, the authors are to be congratulated for describing a cheaper and safer technique of laparoscopic live donor nephrectomy.

\section{REFERENCES}

1. Simforoosh N, Basiri A, Tabibi A, Shakhssalim N: Laparoscopic donor nephrectomy — an Iranian model for developing countries: a cost-effective no-rush approach. Exp Clin Transplant. 2004; 2: 249-53.

2. Chan D, Bishoff JT, Ratner L, Kavoussi LR, Jarrett TW: Endovascular gastrointestinal stapler device malfunction during laparoscopic nephrectomy: early recognition and management. J Urol. 2000; 164: 319-21.

3. Elliott SP, Joel AB, Meng MV, Stoller ML: Bursting strength with various methods of renal artery ligation and potential mechanisms of failure. J Endourol. 2005; 19: 307-11.

4. Meng MV, Freise CE, Kang SM, Duh QY, Stoller ML: Techniques to optimize vascular control during laparoscopic donor nephrectomy. Urology. 2003; 61: 93-7; discussion 97-8.

Dr. Sidney C. Abreu Urological Hospital of Brasilia Brasilia, DF, Brazil E-mail: sidneyabreu@hotmail.com 